\title{
Impact of self-rated osteoarthritis severity in an employed population: Cross-sectional analysis of data from the national health and wellness
}

\section{survey}

Marco daCosta DiBonaventura', Shaloo Gupta ${ }^{1}$, Margaret McDonald ${ }^{2}$, Alesia Sadosky²*, Dan Pettitt ${ }^{2}$ and Stuart Silverman ${ }^{3}$

\begin{abstract}
Background: Although osteoarthritis $(\mathrm{OA})$ often affects older persons, it has a profound effect on individuals actively employed. Despite reports of reduced productivity among workers with OA, data are limited regarding the impact of OA among workers. The objective of this study was to evaluate the impact of self-rated OA severity on quality of life, healthcare resource utilization, productivity and costs in an employed population relative to employed individuals without OA.

Methods: This cross-sectional analysis used data derived from the 2009 National Health and Wellness Survey (NHWS). Multivariable analyses characterized outcomes and costs (direct medical costs and indirect) among workers (full-time, part-time, or self-employed) $\geq 20$ years of age who were diagnosed with OA and who self-rated their OA severity as mild, moderate, or severe relative to workers without OA. Evaluated outcomes included productivity, assessed using the Work Productivity and Impairment (WPAl) scale; health-related quality of life, using the SF-12v2 Health Survey; and healthcare resource utilization.

Results: 4,876 workers reported being diagnosed with OA (45.0\% mild, 45.9\% moderate, and 9.1\% severe); 34,896 workers comprised the non-OA comparator cohort. There was a greater proportion of females in the OA cohort (55.5\% vs 45.6\%; $P<0.0001)$ and more individuals in the $40-64$ year and $\geq 65$ year age ranges $(P<0.0001)$. As OA severity increased, workers reported more frequent pain, poorer quality of life, greater use of specific healthcare resources (hospitalizations) and reduced productivity. All outcomes indicated a significantly greater burden among workers with $\mathrm{OA}$ relative to those without $\mathrm{OA}(P<0.0001)$. Estimated total annual costs per worker were $\$ 9,801$ for mild OA, $\$ 14,761$ for moderate OA, $\$ 22,111$ for severe OA compared with $\$ 7,901$ for workers without OA $(P<$ 0.0001).
\end{abstract}

Conclusions: Workers with OA were characterized by significant disease and economic burdens relative to workers without OA that substantially increased with greater self-rated OA severity. Greater levels of OA severity were associated with reductions in quality of life and productivity, and increases in healthcare resource utilization and costs.

Keywords: Osteoarthritis, Burden, Workforce, Productivity, Quality of life

\footnotetext{
* Correspondence: alesia.sadosky@pfizer.com

${ }^{2}$ Pfizer Inc., 235 East 42nd Street, New York, NY 10017, USA

Full list of author information is available at the end of the article
} 


\section{Background}

Osteoarthritis (OA) ranks among the top causes of disability in the United States (US) [1] and is one of the leading causes of years of living with disability worldwide [2]. OA is also associated with substantial economic and societal burdens resulting from functional impairment, decreased quality of life, and increased healthcare resource utilization [3-8].

Although it has traditionally been considered a disease affecting an older population, OA has a profound effect on individuals who are still active participants in the workforce, often resulting in reduced productivity [8-12]. Despite the consistent reports of reduced productivity among workers with OA, data are still limited regarding the impact of $\mathrm{OA}$ among workers, and several studies have lumped OA with rheumatoid arthritis when evaluating employed populations [13-16]. One OA-specific study, which focused on absenteeism, made direct comparisons with a non-OA cohort [8].

However, presenteeism, generally defined as reduced productivity while at work, and suggested to be the primary source of lost productive time [17] was not examined. The Longitudinal Examination of Arthritis Pain (LEAP) study suggested that weekly fluctuations in OA pain were associated with changes in work absenteeism [18], and a more recent study suggested that OA-related pain has a profound impact on both absenteeism and presenteeism among employed individuals relative to those without OA pain [11]. However, the extent to which severity of $\mathrm{OA}$ as a condition may differentially affect outcomes among workers has not been previously considered.

Recent findings of significant relationships between patient self-rated OA severity and other outcomes, including pain, function, productivity, and costs in both US and European populations suggest that self-report of OA severity provides an accurate and tangible assessment of patients' perceptions of their disease [19-21]. patients' self-report of OA severity thus may be a useful approach to evaluate the impact and burden of OA in workers. The purpose of this study was to evaluate the impact of patient-rated OA severity on productivity and other outcomes including health-related quality of life (HRQoL), healthcare resource utilization, and costs in employed individuals relative to employed individuals without OA. Since both direct and indirect costs are evaluated, this study can be considered as taking the societal perspective.

\section{Methods}

\section{Data source and population}

Data were derived from the 2009 National Health and Wellness Survey (NHWS), a cross-sectional, self- administered, internet-based questionnaire administered annually to a nationwide sample of adults ( $\geq 18$ years of age). The NHWS includes information on 75,000 individuals in the US and uses a random stratified sampling framework to ensure representativeness to the US population http://www.chsinternational.com/nhws.html. Comparisons of NHWS data with other sources (e.g. NHANES, NHIS) have been made elsewhere [22,23]. The NHWS was granted Institutional Review Board approval by Essex IRB (Lebanon, NJ; Protocol Number: CHS-NHWS-US2009-20045); all subjects provide informed consent prior to participation in the survey.

This analysis used data only for respondents $\geq 20$ years of age and currently employed full-time, part-time, or self-employed. Workers meeting these criteria were categorized into four cohorts: mild OA, moderate OA, severe OA, and no OA. Workers in the OA groups were assigned based on self-reporting a diagnosis of OA ("Has your condition been diagnosed by a physician?", "yes" vs "no") and their responses to their severity of OA ("How severe is your arthritis?","mild" vs "moderate" vs "severe"). Subjects who did not report experiencing OA comprised the non-OA referent group.

\section{Outcomes}

The demographic and health characteristics of the overall OA and non-OA cohorts were characterized and compared.

Subjects also reported on the presence of any pain and arthritis-related pain during the past 30 days, and rated their pain interference with normal work activities including work outside the home and housework ("not at all," "a little bit," "moderately" "quite a bit," and "extremely").

Work productivity was assessed using the Work Productivity and Activity Impairment (WPAI) scale [24]. The WPAI, not specific to OA, consists of four subscales that evaluate absenteeism, presenteeism, overall work impairment, and activity impairment during the previous seven days, generated in the form of percentages; higher values indicate greater impairment.

HRQoL was assessed using the physical (PCS) and mental component summary (MCS) scores from the self-reported SF-12v2 Health Survey [25], a validated measure for evaluating HRQoL. The PCS and MCS scores are normed to the US population (mean $=50$, standard deviation $=10$ ) and vary from 0 to 100 ; higher scores indicate better HRQoL. Health utility scores, calculated from the SF-6D and ranging from 0.29 to 1 provided a preference-based single index measure for health status [26].

Healthcare resource utilization within the past six months was self-reported by workers and included 
number of provider visits for both traditional healthcare (physician, emergency room [ER], and hospitalizations) and non-traditional healthcare e.g., acupuncturist, herbalist, etc.

Direct medical costs, which included physician visits, ER visits, and hospitalizations were estimated by multiplying the units of resource categories for six months by two to project annual number of visits, and then multiplying by the average cost of the resource derived from the Medical Expenditure Panel Survey database [27-29]. Indirect costs associated with lost productivity, regardless of causality, were calculated using the method of Lofland et al [30] based on data from the WPAI and median annual income values obtained through the Bureau of Labor Statistics (BLS) [31]. For each respondent, the percent overall work impairment (obtained from the WPAI) was multiplied by the annual income. Direct and indirect costs were summed to estimate total costs.

\section{Analyses}

For categorical variables, chi-square tests were used, while analysis of variance (ANOVA) was used for continuous variables. A Bonferroni correction was applied to adjust for multiple comparisons; the resulting threshold for statistical significance is 0.001 .

Analyses of quality of life were performed using multivariable models with the following demographic and clinical characteristics as covariates: age range (coded as $20-39$ vs $40-64$ and $\geq 65$ years), gender, race/ethnicity (coded as non-Hispanic white, non-Hispanic black, Hispanic, or other), education (more than high school vs high school equivalent degree or less), income $(<\$ 25 \mathrm{~K}$, $\$ 25 \mathrm{~K}$ to $<\$ 50 \mathrm{~K}, \$ 50 \mathrm{~K}$ to $<\$ 75 \mathrm{~K}, \geq \$ 75 \mathrm{~K}$, or decline to answer), Charlson Comorbidity Index [32] (CCI; dichotomized as 0 vs $\geq 1$ because of the skewness of the distribution), health insurance (yes vs no), BMI (underweight [BMI < 18.5], normal [BMI 18.5 to $<25$ ], overweight BMI 25 to $<30]$, obese [BMI $\geq 30]$, or decline to answer), employment (full-time, part-time, or selfemployed), traditional healthcare visits (yes vs no), nontraditional healthcare visits (yes vs no), prescription drug use (yes vs no), ER visits (yes vs no), hospitalization (yes vs no) and experiencing pain in the past month (yes vs no).

Generalized linear models (GLMs) were fitted to predict work productivity, and activity impairment for the OA groups [33]. As work productivity impairment and activity impairment are often highly skewed, the GLMs specified a negative binomial distribution, testing whether adjusted log counts (controlling for covariates) differed across groups [34]. The multiplicative dispersion parameter was also added to adjust the standard errors to account for slight model under-dispersion, and antilogs of the regression estimates were calculated to yield rate ratios relative to no-OA [33]; rate ratios represent the $\mathrm{x}$-fold difference in outcome relative to the referent. The overall effect of age on work productivity was evaluated from the individual regression analyses, and rate ratios were calculated for age categories of 4064 years and $\geq 65$ years relative to workers 20-39 years of age.

Determination and analysis of traditional healthcare resource utilization and direct costs were not adjusted for covariates; an analysis of indirect costs adjusting for the covariates used in the multivariable models was performed post-hoc. For non-traditional healthcare utilization, logistic regression was conducted to predict nontraditional healthcare provider visits (at least one visit vs none) based on OA severity and controlling for the covariates noted above. Analyses were run using SAS version 9.1 (SAS Institute Inc., Cary, NC, USA).

\section{Results}

From the total US NHWS population, 33,765 respondents aged $\geq 20$ years were not currently employed and were excluded from the analyses; of these excluded respondents, 13,178 (39.0\%) were $\geq 65$ years old. A total of 39,772 individuals met the inclusion criteria; 4,876 workers who reported being diagnosed with $\mathrm{OA}$ and 34,896 workers who served as the no-OA comparator cohort. Among workers with OA, severity was rated as mild, moderate, and severe by $45.0 \%, 45.9 \%$, and $9.1 \%$ of individuals, respectively.

Demographic and clinical characteristics are shown in Table 1 . The population was primarily non-Hispanic whites $(66.2 \%$ to $75.2 \%)$, and overall, there was a greater proportion of females in the OA cohort $(53.9 \%$ vs $45.6 \%)$., Relative to workers without OA, workers with OA were characterized by greater proportions of individuals in the 40 to 64 year and $\geq 65$ year age ranges, and by higher proportions of individuals meeting the BMI criteria of obesity $\left(\geq 30 \mathrm{~m}^{2} / \mathrm{kg}\right)$.

The proportion of workers with OA reporting any pain and arthritis-related pain during the past 30 days increased at higher self-rated OA severity levels (Figure 1A). The overall effect for both pain categories was significant relative to the non-OA workers (both $\mathrm{p}<$ 0.0001) (Figure 1A). Significantly higher proportions of workers with OA reported greater pain interference with daily activities including work outside the home and housework relative to non-OA workers (Figure 1B; $\mathrm{p}<0.0001)$. As OA severity increased, the proportion of workers reporting greater levels of pain interference also increased.

Workers with mild, moderate and severe OA reported significantly worsening adjusted SF-12v2 PCS scores as severity level increased ( $p<0.0001)$, and for MCS, there 
Table 1 Weighted univariate statistics (to reflect the US population) for demographic characteristics of workers with osteoarthritis (OA) by self-reported severity category compared with employees without osteoarthritis

\begin{tabular}{|c|c|c|c|c|c|c|c|c|}
\hline \multirow[t]{3}{*}{ Variable } & \multicolumn{6}{|c|}{$O A(n=4,876)$} & \multicolumn{2}{|c|}{ Without OA $(n=34,896)$} \\
\hline & \multicolumn{2}{|c|}{ Mild $(n=2,192)$} & \multicolumn{2}{|c|}{ Moderate $(n=2,240)$} & \multicolumn{2}{|r|}{ Severe $(n=444)$} & \multirow[t]{2}{*}{$\mathbf{n}$} & \multirow{2}{*}{$\begin{array}{l}\text { Weighted percen } \\
\text { (SE) }\end{array}$} \\
\hline & $\mathrm{n}$ & $\begin{array}{l}\text { Weighted percent } \\
\text { (SE) }\end{array}$ & $\mathbf{n}$ & $\begin{array}{l}\text { Weighted percent } \\
\text { (SE) }\end{array}$ & $\mathrm{n}$ & $\begin{array}{l}\text { Weighted percent } \\
\text { (SE) }\end{array}$ & & \\
\hline \multicolumn{9}{|l|}{ Age range } \\
\hline 20-39 years & 338 & $18.6(0.9)$ & 298 & $16.1(0.9)$ & 49 & $13.0(1.8)$ & 15,705 & $49.7(0.3)$ \\
\hline $40-64$ years & 1,339 & $65.0(1.1)$ & 1,447 & $68.8(1.1)$ & 312 & $74.0(2.7)$ & 16,926 & $46.6(0.3)$ \\
\hline$\geq 65$ years & 515 & $16.42(0.9)$ & 495 & $15.1(0.9)$ & 83 & $13.0(2.5)$ & 2,265 & $3.7(0.1)$ \\
\hline \multicolumn{9}{|l|}{ Gender } \\
\hline Male & 1,120 & $49.2(1.2)$ & 1,008 & $44.1(1.2)$ & 190 & $41.7(2.6)$ & 18,460 & $54.4(0.3)$ \\
\hline Female & 1,072 & $50.8(1.2)$ & 1,232 & $56.0(1.2)$ & 254 & $58.4(2.6)$ & 16,436 & $45.6(0.3)$ \\
\hline \multicolumn{9}{|l|}{ Race/ethnicity } \\
\hline White, non- Hispanic & 1,765 & $75.2(1.1)$ & 1,757 & $73.1(1.1)$ & 338 & $69.7(2.9)$ & 24,279 & $66.2(0.3)$ \\
\hline Black, non- Hispanic & 174 & $8.8(0.7)$ & 223 & $10.6(0.8)$ & 63 & $16.5(2.6)$ & 4,143 & $12.1(0.2)$ \\
\hline Hispanic white & 68 & $5.8(0.7)$ & 80 & $6.6(0.7)$ & 18 & $6.6(1.5)$ & 1,959 & $8.6(0.2)$ \\
\hline Hispanic black & 3 & $0.3(0.1)$ & 7 & $0.6(0.2)$ & 2 & $0.6(0.4)$ & 148 & $0.7(0.1)$ \\
\hline Other & 182 & $9.9(0.7)$ & 173 & $9.2(0.7)$ & 23 & $6.6(1.4)$ & 4,367 & $12.5(0.2)$ \\
\hline \multicolumn{9}{|l|}{ Education } \\
\hline$\leq$ High school graduate & 312 & $15.1(0.9)$ & 385 & $17.4(0.9)$ & 99 & $22.5(2.2)$ & 5,791 & $17.0(0.2)$ \\
\hline$>$ High school & 1,880 & $84.9(0.9)$ & 1,855 & $82.7(0.9)$ & 345 & $77.5(2.2)$ & 29,104 & $83.0(0.2)$ \\
\hline \multicolumn{9}{|l|}{ Employment } \\
\hline Full time & 1,297 & $61.2(1.1)$ & 1,282 & $59.5(1.2)$ & 236 & $53.3(2.8)$ & 24,473 & $71.3(0.3)$ \\
\hline Part time & 557 & $23.3(1.0)$ & 586 & $24.8(1.1)$ & 106 & $24.3(2.7)$ & 6,442 & $17.9(0.2)$ \\
\hline Self- employed & 338 & $15.5(0.9)$ & 372 & $15.7(0.9)$ & 102 & $22.5(2.1)$ & 3,981 & $10.8 \pm 0.2)$ \\
\hline \multicolumn{9}{|l|}{ Income } \\
\hline$<\$ 25,000$ & 213 & $9.6(0.7)$ & 291 & $13.4(0.8)$ & 89 & $20.0(2.1)$ & 3,906 & $11.7(0.2)$ \\
\hline$\$ 25,000$ to $\$ 49,999$ & 595 & $27.1(1.0)$ & 703 & $31.4(1.1)$ & 131 & $28.6(2.3)$ & 10,045 & $29.2(0.3)$ \\
\hline$\$ 50,000$ to $\$ 74,999$ & 560 & $25.7(1.0)$ & 531 & $23.8(1.0)$ & 90 & $20.2(2.0)$ & 8,461 & $24.2(0.2)$ \\
\hline$\geq \$ 75,000$ & 711 & $31.8(1.1)$ & 619 & $27.6(1.0)$ & 108 & $25.2(2.7)$ & 10,971 & $30.8(0.3)$ \\
\hline Declined to answer & 113 & $5.8(0.6)$ & 96 & $3.9(0.4)$ & 26 & $6.0(1.2)$ & 1,513 & $4.2(0.1)$ \\
\hline \multicolumn{9}{|l|}{ Health insurance } \\
\hline Yes & 1,955 & $88.2(0.8)$ & 1,951 & $86.0(0.8)$ & 386 & $86.0(1.8)$ & 28,731 & $81.3(0.2)$ \\
\hline No & 237 & $11.8(0.8)$ & 289 & $14.0(0.8)$ & 58 & $14.0(1.8)$ & 6,165 & $18.7(0.2)$ \\
\hline \multicolumn{9}{|l|}{$\mathrm{BMI}\left(\mathrm{m}^{2} / \mathrm{kg}\right)$} \\
\hline Underweight(< 18.5) & 19 & $1.0(0.3)$ & 22 & $0.8(0.2)$ & 3 & $0.7(0.4)$ & 604 & $1.8(0.1)$ \\
\hline Normal(18.5 to < 25) & 527 & $25.0(1.0)$ & 431 & $20.2(1.0)$ & 74 & $18.7(2.7)$ & 11,273 & $32.6(0.3)$ \\
\hline Overweight ( 25 to < 30) & 726 & $32.9(1.1)$ & 722 & $31.9(1.1)$ & 130 & $27.9(2.3)$ & 11,761 & $33.6(0.3)$ \\
\hline Obese $(\geq 30)$ & 890 & $39.8(1.1)$ & 1,027 & $45.3(1.2)$ & 229 & $51.0(2.7)$ & 10,635 & $30.2(0.3)$ \\
\hline Declined to answer & 30 & $1.3(0.3)$ & 38 & $1.7(0.3)$ & 8 & $1.7(0.6)$ & 623 & $1.8(0.1)$ \\
\hline \multicolumn{9}{|l|}{$\begin{array}{l}\text { Charlson Comorbidity Index } \\
\text { (CCl) }\end{array}$} \\
\hline $\mathrm{CCl}$ of 0 & 1,437 & $67.2(1.1)$ & 1,296 & $59.1(1.1)$ & 213 & $47.7(2.7)$ & 28,294 & $82.1(0.2)$ \\
\hline $\mathrm{CCl}$ of 1 or more & 755 & $32.8(1.1)$ & 944 & $40.9(1.1)$ & 231 & $52.6(2.7)$ & 6,602 & $17.9(0.2)$ \\
\hline
\end{tabular}


A

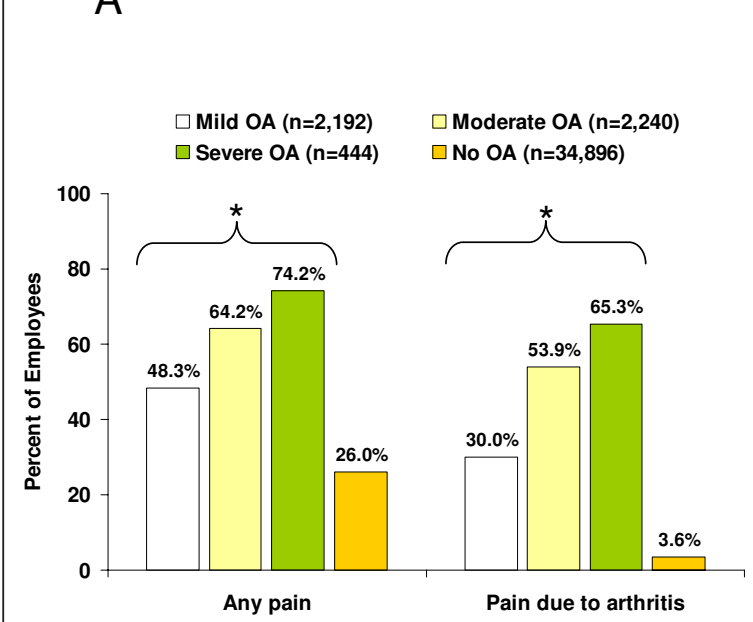

B

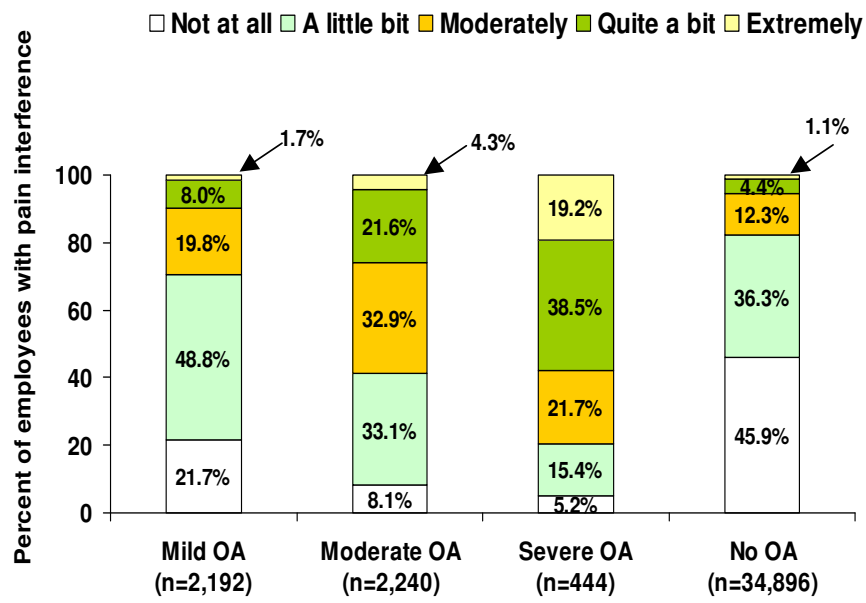

Figure 1 Pain and pain-related interference among workers with osteoarthritis (OA) by self-rated OA severity and workers without OA. A) Proportion of workers reporting any pain and arthritis-related pain. ${ }^{*} p<0.0001$ across severity levels vs no OA. B) Proportion of workers reporting pain interference with normal work activities including work outside the home and housework. $p<0.0001$ across severity levels vs no OA for each category of pain interference.

was a significant increase in the mild OA group compared with non-OA workers (Figure 2A). After controlling for covariates, workers with moderate and severe OA reported health utility scores significantly lower, by 0.04 and 0.08 points, respectively, relative to workers without OA (Figure 2B); there was no difference between mild $\mathrm{OA}$ and no OA.

Work and activity impairment (Figure 3A) showed consistently greater impairment among workers with OA relative to those without OA; impairment increased with increasing OA severity. Lost productivity due to presenteeism was approximately 3-4 times greater than that due to absenteeism across all cohorts even among workers without OA. Overall, workers with OA decreased their productivity by approximately one-third; those with severe OA had almost a $50 \%$ reduction in work time. The adjusted rate ratio (Figure $3 \mathrm{~B}$ ) indicates a difference in magnitude of impairment of 1.39 for absenteeism in the moderate OA group (i.e. $39 \%$ more absenteeism than workers without OA). Workers with moderate and severe OA reported significantly higher percentages of absenteeism, presenteeism, overall work impairment, and activity impairment relative to workers without OA ( $\mathrm{p}<0.001)$; no differences were found for the mild OA group, since the $99 \%$ CI crosses 1, indicating lack of evidence for differences in productivity among workers with mild OA relative to workers with no OA. In terms of hours lost, workers with mild, moderate, and severe OA lost a mean \pm standard deviation of $1.6 \pm 5.7,2.5 \pm 7.1$, and $4.8 \pm 9.7 \mathrm{~h}$, respectively, relative to workers with no OA $(1.3 \pm 5.6 \mathrm{~h}$; overall $\mathrm{p}<$
0.0001). Similarly, hours lost due to presenteeism were $5.86 \pm 8.1$ for mild OA, $9.37 \pm 9.6$ for moderate OA, and $12.5 \pm 12.0$ for severe OA relative to workers without OA $(5.05 \pm 8.5$; overall $\mathrm{p}<0.0001)$.

Evaluation of the impact of age on productivity among workers with OA (Table 2) showed that work productivity loss was greater in younger workers. Relative to workers 20-39 years of age, workers in the 40-64-year age group had approximately 1.4 times less absenteeism, presenteeism, and overall work impairment. Similarly, workers $\geq 65$ years had 2.7, 2.5, and 2.4 times less absenteeism, presenteeism, and overall work impairment, respectively. As worker age increased, so did the proportion of self-employed individuals, from $7.5 \%$ in those $20-39$ years of age, to $13.3 \%$ and $29 \%$ in the middle and the older age groups. Similarly, there appeared to be an increase in the proportion of individuals employed part-time in the older age group (43.1\%) relative to the middle-age (16.43\%) and younger (18.2\%) age groups.

Unadjusted traditional healthcare visits over the prior 6 months were significantly greater among workers with OA relative to no OA ( $<<0.0001)$; the proportion of workers with these visits were generally similar across OA severity levels (Table 3). There was significantly greater use of ER visits and hospitalizations with increasing OA severity $(\mathrm{p}<0.0001)$. Although with increasing $\mathrm{OA}$ severity there were slight increases in the proportion of subjects using non-traditional healthcare resources (Table 3), logistic regression analysis showed that non-traditional resource utilization decreased at 


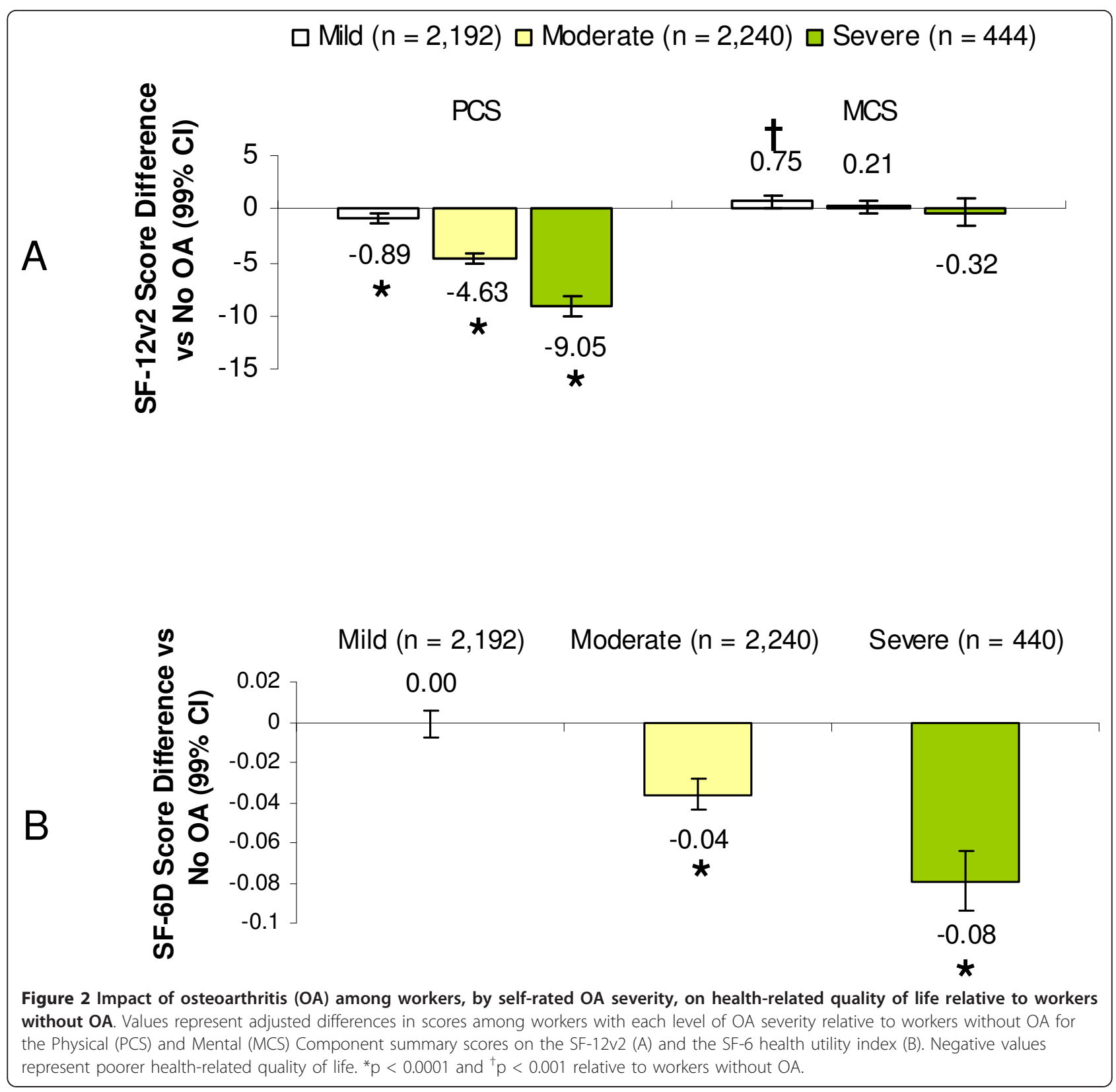

higher OA severity levels relative to the non-OA cohort. The calculated odds ratios for a visit to a non-traditional healthcare provider showed that subjects with mild OA were 1.25 times more likely $(99 \%$ CI $1.09,1.43)$ to visit a non-traditional healthcare provider than workers without OA ( $p=0.0007)$, although there were no significant differences between the moderate and severe OA workers relative to non-OA workers; the calculated odds ratios were $1.12(99 \%$ CI $0.97,1.28)$ and 0.92 (99\% CI $0.69,1.22$ ) for moderate and severe OA, respectively. The mean number of prescriptions over the prior 6 months increased at greater levels of OA severity, and was significantly greater than workers without OA (Table 3)

Estimated unadjusted annual total costs per worker (Figure 4) were \$9,801 for mild OA, \$14,761 for moderate OA, and $\$ 22,111$ for severe OA, compared with $\$ 7,901$ per worker without OA $(p<0.0001)$. Costs were higher with increasing OA severity, and were significantly higher relative to workers without OA ( $\mathrm{p}<$ 0.0001) (Figure 4). Indirect costs, based on lost productivity, were the primary driver of costs, accounting for $70 \%-74 \%$ of total costs, even among workers without OA. In workers with moderate and severe OA, the 


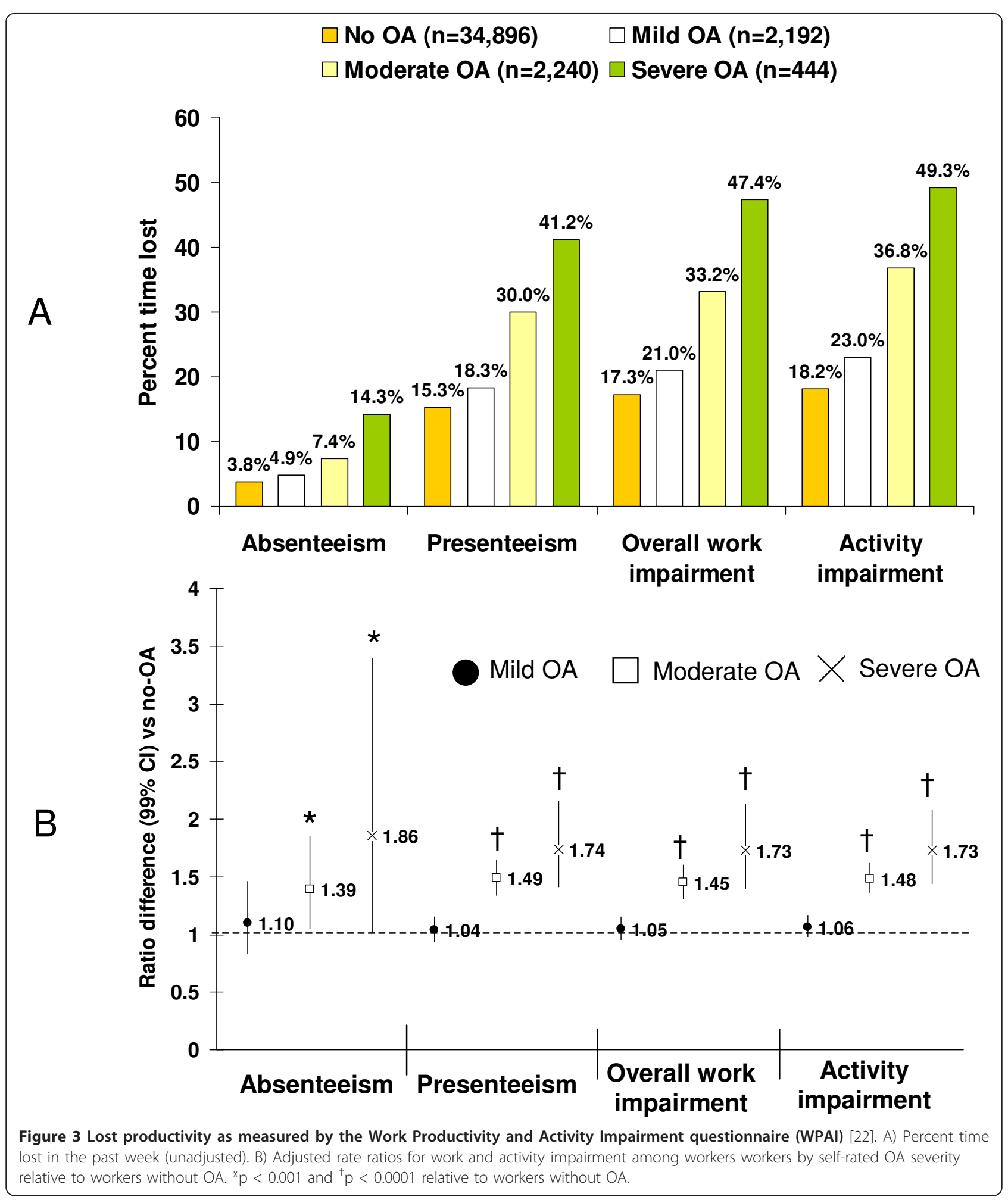

unadjusted indirect costs of $\$ 10,968$ and $\$ 15,596$, respectively, were 2- and 3-fold higher than workers without OA $(\$ 5,854)$. When indirect costs were adjusted for covariates in the multivariable models, these costs were lower than unadjusted costs. However, the adjusted indirect costs were significantly greater $(\mathrm{p}<0.0001)$ among patients with moderate $(\$ 7,413 ; 99 \%$ CI $\$ 6,734$, $\$ 8,161)$ and severe OA $(\$ 8,852 ; 99 \%$ CI $\$ 7,177, \$ 10,918)$ 
Table 2 Effect of age on work and productivity impairment among workers with osteoarthritis.

\begin{tabular}{|c|c|c|c|c|}
\hline \multirow[t]{2}{*}{ WPAI Question } & \multicolumn{2}{|c|}{$40-64$ years of age $(n=1,339)$} & \multicolumn{2}{|c|}{$\geq 65$ years of age $(n=515)$} \\
\hline & Rate ratio $(95 \% \mathrm{Cl})$ & p-value & Rate ratio $(95 \% \mathrm{Cl})$ & p-value \\
\hline Absenteeism & $0.707(0.614,0.815)$ & $<0.0001$ & $0.376(0.289,0.489)$ & $<0.0001$ \\
\hline Presenteeism & $0.733(0.698,0.769)$ & $<0.0001$ & $0.406(0.369,0.445)$ & $<0.0001$ \\
\hline Overall work impairment & $0.737(0.702,0.773)$ & $<0.0001$ & $0.421(0.384,0.462)$ & $<0.0001$ \\
\hline Activity impairment & $0.778(0.745,0811)$ & $<0.0001$ & $0.512(0.472,0.555)$ & $<0.0001$ \\
\hline
\end{tabular}

Rate ratios, adjusted for other covariates, are relative to the referent of workers $20-39$ years of age $(n=338)$. A rate ratio $<1$ indicates a reduction relative to the referent, and the reciprocal of the rate ratio indicates the magnitude of the reduction

relative to no-OA $(\$ 5,140 ; 99 \%$ CI $\$ 5,021, \$ 5,262)$, although there was no difference between no-OA and mild OA $(\$ 5,392 ; 99 \%$ CI $\$ 4,905, \$ 5,927)$.

\section{Discussion}

Self-report of OA severity has been shown to be accurate and relevant in clinical practice [19-21]. This study provides a practical application of using self-report as an indicator of OA severity and demonstrates that as selfrated OA severity increases, there is a greater burden relative to workers without $\mathrm{OA}$.

Many of the demographic differences that were identified between the OA and non-OA cohorts are consistent with what may be expected regarding the epidemiology and risk factors for OA (older, female, non-Hispanic white, greater comorbidities, tendency toward obesity). These variables were included as covariates in the multivariable analyses of quality of life and productivity, and thus the observed differences in these outcomes were likely related to the presence of OA.

Since epidemiologic data on individuals with OA younger than 45 years is sparse, it is interesting to note that the prevalence of OA was $4.2 \%$ for all workers 20 39 years of age, and that among workers with OA, $16.9 \%$ were in this age group. Additionally, approximately half of the workers (50.7\%) with OA in this age group rated their $\mathrm{OA}$ as at least moderate severity.
These data indicate that $\mathrm{OA}$ is likely to be more prevalent and have a greater impact in a younger population than has previously been thought based on the consideration of OA primarily as an age-related disease.

Workers with OA reported significantly lower health status relative to non-OA workers as measured by SF$6 \mathrm{D}$ utility values. The observed differences of -0.04 points and -0.08 points for moderate and severe OA relative to non-OA, respectively, were clinically significant; differences of at least 0.03 points are proposed to be clinically meaningful [35]. Pairwise differences in health status among OA severity levels also exceeded 0.03 , suggesting clinical significance. This trend of poorer health with increasing self-rated OA severity is consistent with previous observations using the EuroQol (EQ-5D) health index in US and European OA populations $[20,21]$.

OA affects physical functioning, and it is therefore not surprising that effects were greater on physical components (PCS) of HRQoL than on mental components (MCS). Since differences of greater than 3 points between groups are considered clinically significant [36], the differences in PCS scores were clinically meaningful as well as statistically significant. In contrast, there was little change in the MCS, and although the score among workers with mild OA was statistically higher than among workers without OA, this is likely due to

Table 3 Unadjusted 6-month healthcare resource utilization among workers with osteoarthritis (OA) by self-reported severity category compared with workers without osteoarthritis

\begin{tabular}{|c|c|c|c|c|c|}
\hline \multirow[t]{2}{*}{ Health Resource Category } & \multicolumn{3}{|c|}{$O A(n=4,876)$} & \multirow{2}{*}{$\begin{array}{l}\text { Without OA }(n= \\
34,896)\end{array}$} & \multirow{2}{*}{$\begin{array}{l}\text { p-value (OA vs no } \\
\text { OA) }\end{array}$} \\
\hline & $\begin{array}{l}\text { Mild }(n= \\
2,192)\end{array}$ & $\begin{array}{l}\text { Moderate }(\mathrm{n}= \\
2,240)\end{array}$ & $\begin{array}{l}\text { Severe }(n= \\
444)\end{array}$ & & \\
\hline $\begin{array}{l}\text { Traditional healthcare visits, weighted percent } \\
\text { (SE) }\end{array}$ & $88.3(0.7)$ & $90.0(0.7)$ & $89.34(1.6)$ & $71.7(0.3)$ & $<0.0001$ \\
\hline Emergency room visits, weighted percent (SE) & $13.2(0.8)$ & $18.3(1.0)$ & $28.36(2.8)$ & $10.2(0.2)$ & $<0.0001$ \\
\hline Hospitalizations, weighted percent (SE) & $8.5(0.7)$ & $11.1(0.8)$ & $20.9(2.1)$ & $5.1(0.1)$ & $<0.0001$ \\
\hline $\begin{array}{l}\text { Non traditional healthcare visits, weighted } \\
\text { percent (SE) }\end{array}$ & $30.2(1.1)$ & $31.9(1.1)$ & $34.3(2.8)$ & $20.1(0.2)$ & $<0.0001$ \\
\hline $\begin{array}{l}\text { Number of prescriptions, mean } \pm \text { standard } \\
\text { deviation }\end{array}$ & $3.7 \pm 4.1$ & $5.0 \pm 4.8$ & $6.4 \pm 5.5$ & $2.0 \pm 3.2$ & $<0.0001$ \\
\hline
\end{tabular}




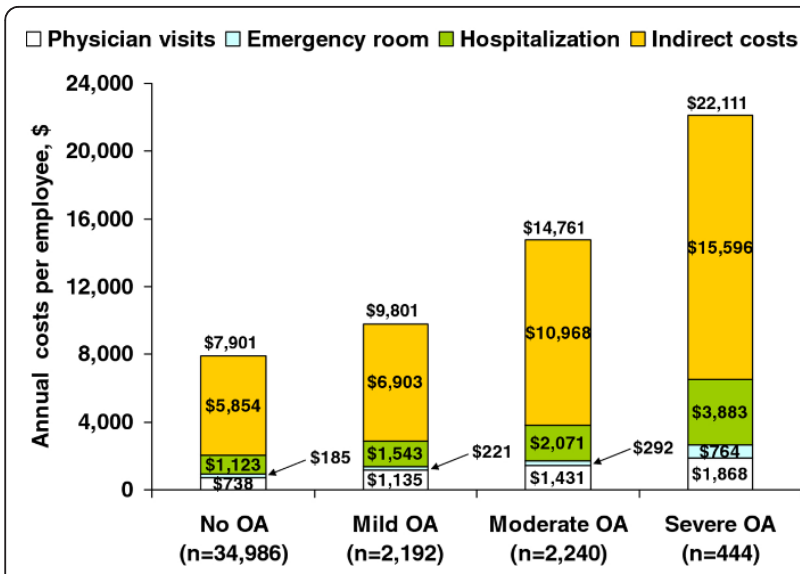

Figure 4 Annual unadjusted costs per individual among workers with osteoarthritis $(O A)$ by self-rated $O A$ severity and workers without $\mathbf{O A}$. Overall $p<0.0001$ for each cost category relative to workers with no $\mathrm{OA}$.

measurement error, possibly because of the large population. Of note, both the PCS and MCS scores are normed to the US population, enhancing generalizability.

The frequency of general pain and arthritis pain was significantly greater among workers with $\mathrm{OA}$ relative to those without, and higher at increasing levels of $\mathrm{OA}$ severity. Although OA pain and its treatment are associated with reduced productivity and increased costs $[11,37]$, it remains to be determined whether these effects are related to pain severity, frequency, or both. Pain is likely to be only one of several factors that contribute to patients' perceptions of OA severity, and while experiencing pain in the past month was included as a covariate, pain severity was not. Nevertheless, the pain-related interference, which increased with greater OA severity and was significantly higher than non-OA workers, is consistent with an association between OA severity and specific activities of daily living [19], and provides a foundation for the potential impact of OA severity on work impairment.

Workers with OA were characterized by significantly greater work and activity impairment relative to those without OA, and the separation between cohorts increased with greater OA severity. Among workers with moderate and severe OA, approximately one-third (33.2\%) and one-half (47.4\%) of worker productivity was lost, respectively, compared with $17.3 \%$ among non-OA workers. While several studies evaluated OA-related absenteeism $[8-10,18]$, few data exist on presenteeism, despite presenteeism being suggested as the primary source of lost productivity in the general arthritis population $[13,16,17,38]$. This study confirms presenteeism as the primary source of work impairment in workers with $\mathrm{OA}$, and characterizes the magnitude of this impairment as 3-4 times greater than that due to absenteeism, resulting in loss of more than a day's work/week among workers with moderate and severe OA.

Interestingly, lost productivity decreased with increasing age among workers with OA. The reasons underlying this observation cannot be established based on the data from this study, and few other studies have evaluated OA and its impact across these age groups. Nevertheless, several suggestions may be proposed to account for these data. First, it is possible that at least some of the differences in lost productivity between the younger and older age groups may be explained by the concomitant increase in self-employment and part-time work observed with increasing age. These types of employment, especially the former, may potentially allow workers to benefit from a more flexible work environment, thereby reducing lost productivity. In this regard, it should also be noted that while all individuals were employed at the time of the survey, no information was available on whether workers switched jobs, received accommodations at work for OA disability, or transitioned out and back into the workforce over time. Such workforce transitions have previously been shown to be common among workers with arthritis [14]. Second, coping strategies and selfefficacy, which are prognostic factors for outcomes in individuals with OA [39], are likely to be different among the age groups [40]. Such strategies may also relate to duration of disease, which was not captured in the current study.

The consequences of lost productivity were profound as manifested by their impact on costs. Although indirect costs were the primary cost driver, including among workers without OA, the magnitude of work impairment was especially apparent among workers with moderate and severe OA, resulting in unadjusted indirect costs that were $87 \%$ and $166 \%$ higher, respectively, than among workers without $\mathrm{OA}$, and adjusted indirect costs $44 \%$ and $72 \%$ higher, respectively.

The magnitude of the unadjusted indirect costs $(\$ 6,903, \$ 10.968$, and $\$ 15,596$ for mild, moderate, and severe OA, respectively) is consistent with estimates for employees with mild $(\$ 6,096)$, moderate $(\$ 13,251)$, and severe $(\$ 17,214)$ self-rated OA in a clinical practicederived database [19]. However, they are in contrast to other studies that reported low indirect costs $[9,37,41]$. Since there are no standardized methods for estimating indirect costs in OA [42], these discrepancies may be attributed to differences in populations or methodologies. It is likely that inadequately accounting for presenteeism in other studies contributed to underestimation of costs. Differences in methodology may also account for the observation that our estimated mean medical costs of workers with OA ( $\$ 4,403$ across all severity 
categories) were lower than in other recently reported studies $(\$ 6,984-\$ 8,201)[9,10]$.

The data additionally show that more workers with OA reported use of traditional healthcare, and had associated higher costs across categories than the non-OA workers. The primary driver of direct costs was hospitalizations, likely due to the high cost per event. Although workers with $\mathrm{OA}$ were prescribed significantly more medications than those without OA, this was not included in the costs. Furthermore, whether these visits and medications were specifically related to OA could not be ascertained.

It is worth noting that after adjusting for covariates, non-traditional health provider visits (e.g. acupuncturists, herbalists, etc.) were used by a significantly greater proportion of individuals only among workers with mild OA relative to workers without OA. There is scarce information on utilization and outcomes of non-traditional provider care for OA, possibly because these visits are not generally included in insurance plans or claims databases.

It should be recognized that in the clinical setting, a variety of covariates are likely to impact healthcare-seeking behavior by patients, management strategies by providers, and work-loss-related compensation among employers. However, the resource utilization and total cost analyses were not adjusted for covariates since we wanted to provide a more complete perspective of the burden among these workers; in particular, unadjusted costs are often used to characterize the overall cost burden. Additionally, our multivariable models contained covariates that were outcomes in the resource utilization and costs analysis. Consequently, as a result of using unadjusted values, a conservative approach should be used for interpreting the implications of these analyses.

Strengths of this study include our ability to capture a wide variety of outcomes and the focus on an employed population, since disease burden in an active workforce is of economic importance to a variety of stakeholders. The large sample size and use of population-level analyses based on weighted assessments to reflect the demographic composition of the US population are additional strengths that enhance the generalizability of this study. Conversely, the large sample size may also be considered a limitation, since it is likely that some of the statistical significance could be ascribed to the large population.

Additional limitations include the use of self-report and that the OA diagnosis was not clinically confirmed. The latter could potentially introduce selection bias, since it is possible that workers in both cohorts may not have been clear about whether they had the correct diagnosis for inclusion/exclusion in their respective cohorts. However, given the large sample size, it is likely that the number of workers inappropriately placed in the cohorts would not substantially bias the results. Furthermore, this potential for bias does not preclude patient report as an important resource for evaluating outcomes, especially related to productivity.

Since the WPAI was not OA specific, the observed relationships between $\mathrm{OA}$ and productivity should be considered associative rather than causal. Similarly, the higher resource utilization and costs cannot be ascribed specifically to OA, since there are no claims linking resource use with the disease and symptoms of interest. Nevertheless, lost productivity in workers with OA was higher with increasing OA severity, and resulted in significantly greater indirect costs among workers with OA that may be of special concern to employers.

Although information was obtained on salary ranges and education, the type of employment or worker occupation was not considered. Type of employment is not only a risk factor for OA resulting from specific occupational activities [43,44], but is also likely to affect productivity, since workers with OA may be likely to avoid certain work activities. A similar limitation is that the joint affected was not determined; specific sites of OA (lower back, neck and knee) have been shown to be predictors of greater productivity losses [45] and may also differentially affect healthcare resource utilization and associated costs. It is important to recognize that these factors may have implications for management strategies, and their absence in our analysis may reduce the generalizability of the results.

Although the number of prescribed drugs was captured by patient report, this information could not be used to estimate pharmacotherapy costs, since the source of our data was not a medical claims database. Thus, direct costs are likely to be underestimated. Furthermore, derivation of annual costs was based on extrapolation of 6-month data to 1 year, and may not adequately reflect annual resource utilization.

\section{Conclusions}

Workers with OA had significantly lower productivity and HRQoL, and significantly higher healthcare resource utilization and costs than non-OA workers. Increased OA severity was associated with incremental productivity losses and costs, relative to workers with less severe $\mathrm{OA}$ and to those without OA. Total costs were driven by indirect costs resulting from lower productivity, with presenteeism accounting for the greatest proportion of lost work time. These results illustrate a practical application of asking patients to self-rate their OA severity. The association of these ratings with a variety of outcomes suggests the utility of asking patients to self-rate their disease in clinical practice to provide greater relevancy from the patient's perspective. 
The contribution of OA severity to the patient and economic burdens of this disease was also demonstrated in this study. Such information may be useful to employers and healthcare providers when considering management strategies and workplace accommodations to improve productivity and other outcomes that can help alleviate the burden of OA. The results also suggest that there is a need for additional studies that can stratify by specific sites of OA, as well as by different occupations, and more clearly determine what proportion of the higher resource utilization and costs may be attributable specifically to OA. Studies are also warranted to further evaluate and quantify the direct costs associated with different levels of OA severity.

\section{Abbreviations}

BMI: Body mass index; ER: Emergency room; HRQoL: Health-related quality of life; MCS: Mental component summary of the SF-12v2 Health Survey; NHWS: National Health and Wellness Survey; OA: Osteoarthritis; PCS: Physical component summary of the SF-12v2 Health Survey; WPAl: Work Productivity and Impairment scale.

\section{Acknowledgements}

This study was funded by Pfizer, Inc. Marco DiBonaventura and Shaloo Gupta are employees of Kantar Health, and were paid consultants to Pfizer in the conduct of this study and the development of this manuscript. Editorial assistance was provided by E. Jay Bienen, who was funded by Pfizer, Inc.

Funding

This study was funded by Pfizer, Inc.

\section{Author details}

'Kantar Health, New York, NY, USA. ${ }^{2}$ Pfizer Inc., 235 East 42nd Street, New York, NY 10017, USA. ${ }^{3}$ Cedars-Sinai Medical Center, Los Angeles, CA, USA.

\section{Authors' contributions}

All authors contributed to the study design, statistical analysis plan, results interpretation, and review of the draft manuscript; the final manuscript was read and approved by all authors.

\section{Competing interests}

Alesia Sadosky and Margaret McDonald are employees and stockholders of Pfizer Inc, the sponsor of this study. Dan Pettitt was a Pfizer employee during the conduct of this study. Marco DiBonaventura and Shaloo Gupta are employees of Kantar Health, who conducted the National Health and Wellness Survey and analyzed the data on behalf of Pfizer Inc. Dr Silverman is a consultant to Pfizer and Lilly. Dr. Silverman did not receive financial support for this project.

Received: 25 August 2011 Accepted: 15 March 2012

Published: 15 March 2012

\section{References}

1. Centers for Disease Control and Prevention (CDC): Prevalence and most common causes of disability among adults-United States, 2005. MMWR Morb Mortal Wkly Rep 2009, 58:421-426.

2. Woolf AD, Pfleger B: Burden of major musculoskeletal conditions. Bull World Health Organ 2003, 81:646-656.

3. Dominick KL, Ahern FM, Gold CH, Heller DA: Health-related quality of life and health service use among older adults with osteoarthritis. Arthritis Rheum 2004, 51:326-331.

4. Gupta S, Hawker GA, Laporte A, Croxford R, Coyte PC: The economic burden of disabling hip and knee osteoarthritis $(\mathrm{OA})$ from the perspective of individuals living with this condition. Rheumatology (Oxford) 2005, 44:1531-1537.
5. Rabenda V, Manette C, Lemmens R, Mariani AM, Struvay N, Reginster JY: Direct and indirect costs attributable to osteoarthritis in active subjects. J Rheumatol 2006, 33:1152-1158.

6. Cook C, Pietrobon R, Hegedus E: Osteoarthritis and the impact on quality of life health indicators. Rheumatol Int 2007, 27:315-321.

7. Kotlarz H, Gunnarsson CL, Fang H, Rizzo JA: Insurer and out-of-pocket costs of osteoarthritis in the US: evidence from national survey data. Arthritis Rheum 2009, 60:3546-3553.

8. Kotlarz H, Gunnarsson CL, Fang H, Rizzo JA: Osteoarthritis and absenteeism costs: evidence from US National Survey Data. J Occup Environ Med 2010, 52:263-268.

9. White LA, Birnbaum HG, Kaltenboeck A, Tang J, Mallett D, Robinson RL: Employees with fibromyalgia: medical comorbidity, healthcare costs, and work loss. J Occup Environ Med 2008, 50:13-24.

10. Kleinman N, Harnett J, Melkonian A, Lynch W, Kaplan-Machlis B, Silverman S: Burden of Fibromyalgia and Comparisons With Osteoarthritis in the Workforce. J Occup Environ Med 2009, 51:1384-1393.

11. daCosta DiBonaventura M, Gupta S, McDonald M, Sadosky A: Evaluating the health and economic impact of osteoarthritis pain in the workforce: results from the National Health and Wellness Survey. BMC Musculoskelet Disord 2011, 12:83.

12. McDonald M, DiBonaventura MD, Ullman SJP: Musculoskeletal pain in the workforce: the effects of back, arthritis and fibromyalgia pain on quality of life and work productivity. J Occup Environ Med 2011, 53:765-770.

13. Li X, Gignac MA, Anis AH: The indirect costs of arthritis resulting from unemployment, reduced performance, and occupational changes while at work. Med Care 2006, 44:304-310.

14. Gignac MA, Cao X, Lacaille D, Anis AH, Badley EM: Arthritis-related work transitions: a prospective analysis of reported productivity losses, work changes, and leaving the labor force. Arthritis Rheum 2008, 59:1805-1813.

15. Zhang W, Gignac MA, Beaton D, Tang K, Anis AH: Productivity loss due to presenteeism among patients with arthritis: estimates from 4 instruments. J Rheumatol 2010, 37:1805-1814.

16. Zhang $W$, Koehoorn M, Anis AH: Work productivity among employed Canadians with arthritis. J Occup Environ Med 2010, 52:872-877.

17. Stewart WF, Ricci JA, Chee E, Morganstein D, Lipton R: Lost productive time and cost due to common pain conditions in the US workforce. JAMA 2003, 290:2443-2454.

18. Hutchings A, Calloway M, Choy E, Hooper M, Hunter DJ, Jordan JM, Zhang Y, Baser O, Long S, Palmer L: The Longitudinal Examination of Arthritis Pain (LEAP) study: relationships between weekly fluctuations in patient-rated joint pain and other health outcomes. J Rheumatol 2007, 34:2291-2300.

19. Sadosky A, Bushmakin A, Cappelleri JC, Lionberger DR: Relationship between patient-reported disease severity in osteoarthritis and selfreported pain, function, and work productivity. Arthritis Res Ther 2010, 12: R162.

20. Sadosky A, Cappelleri J, Bushmakin A, Lionberger D: Health status and disease severity in osteoarthritis. [abstract]. J Pain 2010, 11(Suppl):S1.

21. Bushmakin AG, Cappelleri JC, Taylor-Stokes G, Sayers J, Sadosky A, Carroll D, Gosden T, Emery P: Relationship between patient-reported disease severity and other clinical outcomes in osteoarthritis: a European perspective. J Med Econ 2011, 14:381-389.

22. Bolge SC, Doan JF, Kannan H, Baran RW: Association of insomnia with quality of life, work productivity, and activity impairment. Qual Life Res 2009, 18:415-422.

23. DiBonaventura MD, Wagner JS, Yuan Y, L'Italien G, Langley P, Ray Kim W: Humanistic and economic impacts of hepatitis $C$ infection in the United States. J Med Econ 2010, 13:709-718.

24. Reilly MCZ, Dukes EMAS: The validity and reproducibility of a work productivity and activity impairment instrument. PharmacoEconomics 1993, 4:353-365.

25. Ware JE Jr, Kosinski M, Turner-Bowker D, Gandek B: User's Manual for the SF$122^{2^{\mathrm{TM}}}$ Health Survey with a Supplement Documenting SF-12 ${ }^{\circledR}$ Health Survey Lincoln, RI: QualityMetric Incorporated; 2002.

26. Brazier J, Roberts J, Deverill M: The estimation of a preference-based measure of health from the SF-36. J Health Econ 2002, 21:271-292.

27. Machlin S: Expenses for a hospital emergency room visit, 2003. MEPS Statistical Brief No. 111 (2006).[http://meps.ahrq.gov/mepsweb/data_files/ publications/st111/stat111.pdf]. 
28. Machlin S, Carper K: Expenses for Office-Based Physician Visits by Specialty, 2004. MEPS Statistical Brief No. 166 (2007).[http://meps.ahrq. gov/mepsweb/data_files/publications/st166/stat166.pdf].

29. Machlin S, Carper K: Expenses for Hospital Inpatient Stays, 2004. MEPS Statistical Brief No. 164.[http://meps.ahrq.gov/mepsweb/data_files/ publications/st164/stat164.pdf].

30. Lofland JH, Pizzi L, Frick KD: A review of health-related workplace productivity loss instruments. PharmacoEconomics 2004, 22:165-184.

31. United States Department of Labor, United States Bureau of Labor Statistics: Highlights of women's earnings in 2008. Report 1017. [http://www.bls. gov/cps/cpswom2008.pdf].

32. Charlson ME, Pompei P, Ales KL, Mackenzie CR: A new method of classifying prognostic comorbidity in longitudinal studies: development and validation. J Chronic Dis 1987, 40:373-383.

33. Cohen J: Statistical Power Analysis for the Behavioral Sciences. 2 edition. Hillsdale, NJ: Lawrence Erlbaum Associates; 1988

34. Glynn RJ, Buring JE: Ways of measuring rates of recurrent events. BMJ 1996, 312:364-367.

35. Walters SJ, Brazier JE: What is the relationship between the minimally important difference and health state utility values? The case of the SF6D. Health Qual Life Outcomes 2003, 1:4.

36. Hays RD, Morales LS: The RAND-36 measure of health-related quality of life. Ann Med 2001, 33:350-357.

37. White AG, Birnbaum HG, Janagap CC, Buteau L, Schein J: Direct and indirect costs of pain therapy for osteoarthritis in an insured population in the United States. J Occup Environ Med 2008, 50:998-1005.

38. Ricci JA, Stewart WF, Chee E, Leotta C, Foley K, Hochberg MC: Pain exacerbation as a major source of lost productive time in US workers with arthritis. Arthritis Rheum 2005, 53:673-681.

39. Benyon K, Hill S, Zadurian N, Mallen C: Coping strategies and self-efficacy as predictors of outcome in osteoarthritis: a systematic review. Musculoskeletal Care 2010, 8:224-236.

40. Trouillet R, Gana K, Lourel M, Fort I: Predictive value of age for coping: the role of self-efficacy, social support satisfaction and perceived stress. Aging Ment Health 2009, 13:357-366.

41. Maetzel A, Li LC, Pencharz J, Tomlinson G, Bombardier C: The economic burden associated with osteoarthritis, rheumatoid arthritis, and hypertension: a comparative study. Ann Rheum Dis 2004, 63:395-401.

42. Xie F: The need for standardization: a literature review of indirect costs of rheumatoid arthritis and osteoarthritis. Arthritis Rheum 2008, 59:1027-1033

43. Allen KD, Chen JC, Callahan LF, Golightly YM, Helmick CG, Renner JB, Jordan JM: Associations of occupational tasks with knee and hip osteoarthritis: the Johnston County Osteoarthritis Project. J Rheumatol 2010, 37:842-850.

44. McWilliams DF, Leeb BF, Muthuri SG, Doherty M, Zhang W: Occupational risk factors for osteoarthritis of the knee: a meta-analysis. Osteoarthr Cartil 2011, 19:829-839.

45. Sayre EC, Li LC, Kopec JA, Esdaile JM, Bar S, Cibere J: The effect of disease site (knee, hip, hand, foot, lower back or neck) on employment reduction due to osteoarthritis. PLOS One 2010, 5:e10470.

doi:10.1186/1477-7525-10-30

Cite this article as: DiBonaventura et al:: Impact of self-rated osteoarthritis severity in an employed population: Cross-sectional analysis of data from the national health and wellness survey. Health and Quality of Life Outcomes 2012 10:30.

\section{Submit your next manuscript to BioMed Central and take full advantage of:}

- Convenient online submission

- Thorough peer review

- No space constraints or color figure charges

- Immediate publication on acceptance

- Inclusion in PubMed, CAS, Scopus and Google Scholar

- Research which is freely available for redistribution

Submit your manuscript at www.biomedcentral.com/submit 